\title{
Synthesis and Application of XAD-2/Me-BTAP Resin for On-Line Solid Phase Extraction and Determination of Trace Metals in Biological Samples by FAAS
}

\author{
Valfredo Azevedo Lemos, * Graciete Teixeira David and Luana Novaes Santos
}

J. Braz. Chem. Soc., Vol. 17, No. 4, 697-704, 2006.

In page 700, the correct Figure 3 is given bellow:



Figure 3. Effect of $\mathrm{pH}$ on the preconcentration of $\mathrm{Cu}, \mathrm{Co}$ and $\mathrm{Ni}$. 